


\title{
NOTAS FILOSÓFICAS SOBRE LA SOLEDAD EN CIEN AÑOS DE SOLEDAD (1967) DE GABRIEL GARCÍA MÁRQUEZ
}

\author{
PHILOSOPHICAL NOTES ON SOLITUDE IN ONE HUNDRED \\ YEARS OF SOLITUDE (1967) BY GABRIEL GARCÍA MÁRQUEZ
}

\author{
Andrés Lema-Hincapié
}

\begin{abstract}
RESUMEN
No ha sido suficientemente pensado el título de la novela que Gabriel García Márquez publica en 1967. La soledad en el título de esa obra debe ser comprendida como una verdad humana que "toca el corazón" - para usar la metáfora compleja de William Faulkner. Mis argumentos se irán construyendo a partir del recurso a lo que podría ser llamado "anacronismos sugerentes". Gracias a estos anacronismos, haré entrar en diálogo obras y autores que muy seguramente García Márquez no tuvo en mente durante la escritura de sus Cien años de soledad: Michel de Montaigne, Miguel de Unamuno y Xavier Zubiri, por ejemplo. No obstante, espero que este procedimiento saque a la luz posibles sentidos - plausibles, verosímiles- en relación con el concepto que me ocupa: la soledad. Palabras clave: soledad, comunidad fracasada, aislamiento físico, retiro doméstico, García-Márquez.
\end{abstract}

\begin{abstract}
The title of the novel Gabriel García Márquez publishes in 1967 has not been thought enough. I argue that the word solitude in its title should be understood as pointing out at a human truth that "touches the heart" -to use a complex metaphor by William Faulkner. I will build my arguments by referring to what I love to call "suggestive anachronisms". Thanks so such anachronisms, I will make talk together works and authors García Márquez almost surely did not have in mind while he was writing his One Hundred Years of Solitude. I am thinking, for instance, of Michel de Montaigne, Miguel de Unamuno, and Xavier Zubiri. Notwithstanding, it is my hope that, by the means of such a procedure, new possible meanings - plausible ones- can be brought to light in relation to the concept I will be studying throughout my pages, namely, solitude.

Key words: solitude, community at failure, physical isolation, household retreat, García-Márquez.
\end{abstract}

\section{Primeras orientaciones}

Cien años de soledad es un libro triste.

Muchos lectores, y un número no menor de críticos, han sido fácilmente encantados por el poder hechizante de la voz narrativa presente en el libro. El hechizo parece ser causado

Ph.D. Andrés Lema-Hincapié. University of Colorado Denver. Profesor Asociado de Literatura y Cultura Iberoamericanas. Estados Unidos.

Correo electrónico: andres.lema-hincapie@ucdenver.edu

Recepción: 14- 04- 2014

Aceptación: 28- 04- 2014 
por el hecho de que esa voz narrativa no tendría límites cuando se trata de crear historias para sus personajes, de sugerir posibles caminos diegéticos no explorados, de mostrar un asombroso dominio estilístico y léxico, y de exacerbar las ansias insatisfechas de todo lector que quiere conocer más y más sobre tantos personajes e incluso sobre cada uno de los detalles de la obra -por pequeños que estos puedan parecer-.

El carácter inesperado de muchas historias, además, está acompañado constantemente por variados niveles en las intenciones y en los efectos de humor de Cien años de soledad: abundan las exageraciones; los personajes se expresan en sentencias cortas y contundentes de gran ingenio; y hay una cantidad enorme de eso que en el cine lleva el nombre de gags -esto es, un acontecimiento que o bien "violat[es] all laws of nature" ("Speaking of Pictures", 1958, p. 8), o bien viola las normas de prácticas consuetudinarias. El acontecimiento gag, al mismo tiempo, crea un infortunio que no es ni mortalmente perjudicial, ni físicamente terrible, para el personaje que lo sufre.

En otras palabras: la exuberancia imaginativa de Cien años de soledad, su humor sutil o evidente, su maestría verbal y los abre-bocas sobre mundos posibles no narrados, divierten a casi todos los lectores. Aquí la palabra "divierten" retoma su sentido etimológico: GarcíaMárquez en Cien años de soledad confunde hábilmente al lector, llevándolo a recorrer otros lugares, otros senderos - divertere, en latín, significa "to turn away", "desviar de la ruta"- que en lugar de situarlo y de llevarlo directamente a los sentidos existenciales de la obra, lo desorientan y más bien lo pierden. La "diversión" ha sido tan poderosa y tan eficaz que el sentido mismo del título del libro -Cien años de soledad-, por lo general, queda en la desatención y se oculta en la opacidad del olvido. Juzgo necesario distinguir entre la escritura de la experiencia del dolor, del absurdo, y, en este caso, de la soledad, por un lado, y, por otro, la experiencia misma de ese dolor, de ese absurdo, de esa soledad. La escritura puede causar obnubilación en torno de aquello a lo cual apunta. La genialidad de la escritura misma de García-Márquez ensombrece la experiencia misma que la escritura trata de referir. En otros términos: El ensueño creado desde las palabras ha triunfado sobre la referencialidad vital de ellas.

Quiero proponer aquí una interpretación que esté muy alerta a los peligros de ese hechizo. Los peligros siempre acechan en las palabras y en el ritmo melódico de la novela. De este modo, busco reconducir la obra hacia su más profunda y triste verdad antropológica. Esto no deberá entenderse como el intento para negar ni los méritos literarios de la obra, ni las fuertes dosis de humor que hay en ella. Todo lo contrario. Rafael Gutiérrez-Girardot insistió, con verdad, en que "quien en la lectura de las novelas de García Márquez no sienta la necesidad de sonreír [...], se ha extraviado en el primer acceso a esta obra" (Gutiérrez-Girardot, 2011, p. 228). Para Gutiérrez-Girardot, el tipo de humor de García-Márquez recupera una genealogía de autores latinoamericanos. Entre esos autores estarían "la escuela de la ironía de Jorge Luis Borges" (Gutiérrez-Girardot, 2011, p. 228), el autor argentino, así como el humor de la obra de Ricardo Palma, de Perú, la poesía del colombiano León de Greiff, y los cuentos cortos del mexicano Juan José Arreola.

Y, es a partir de esta reconducción interpretativa de Cien años de soledad, que muy seguramente la obra podrá alcanzar una mayor contundencia estética y una verdad existencial fuerte menos proclives a perecer. Aquí conviene utilizar palabras de William Faulkner, uno de los maestros literarios de García-Márquez. En “The Bear”, un cuento de Faulkner incluido en su antología Go Down, Moses (1942), refiriéndose a una obra de John Keats, el personaje de Cass Edmonds caracteriza así los temas explorados por los escritores. Esos temas desbordarían 
el sentido literal de lo escrito. Para el personaje de Isaac McCaslin, en "Ode on a Grecian Urn" de Keats, la voz poética simplemente alude a una chica. No es así, según Cass Edmonds:

\footnotetext{
[Keats] had to talk about something. [...] He was talking about truth. Truth is one. It doesn't change. It covers all things which touch the heart -honor, and pride, and pity, and justice, and courage, and love. Do you see now? [...] Courage and honor and pride, and pity and love of justice and of liberty. They all touch the heart. And what the heart holds to becomes truth, as far as we know truth. (Faulkner, 1942, p. 297)

[Keats] tuvo que hablar sobre algo [...] Él hablaba sobre la verdad. La verdad es una sola. Ella no cambia. Ella tiene que ver con todas las cosas que tocan el corazón -honor, y orgullo, y piedad, y justicia, y coraje, y amor. ¿Lo ves ahora? [...] El coraje y el honor y el orgullo, y la piedad y el amor de justicia y de libertad. Todos ellos tocan el corazón. Y lo que le importa al corazón se convierte en la verdad, hasta donde nosotros conocemos la verdad.
}

En las páginas que siguen argumentaré que para García-Márquez la soledad forma parte, también y fundamentalmente, de esa verdad humana que "toca el corazón". En su comentario de 1967 a Cien años de soledad titulado "Anotado al margen de Cien años de soledad" y aparecido en el número 87 de la revista Eco, el crítico Ernesto Volkening descubría una profundidad ancestral -de vivencia humana en el mito- en relación con el tema de la soledad en la novela de García-Márquez: "La soledad ha de ser concebida, quizás, en el sentido más profundo de una separación de la legendaria tierra de los antepasados, equivalente a las expulsión del Paraíso" (Volkening, 1976a, p. 127). En todo caso, mis argumentos se irán construyendo a partir del recurso a lo que podría ser llamado anacronismos sugerentes. Gracias a estos anacronismos, haré entrar en diálogo obras y autores que muy seguramente García-Márquez no tuvo en mente durante la escritura de Cien años de soledad. No obstante, espero que este procedimiento saque a la luz posibles sentidos -plausibles, verosímiles- en relación con el concepto que me ocupa: la soledad.

\section{García-Márquez interpreta su novela de 1967}

En una entrevista que en 1970 le concedió a Ernesto González-Bermejo, García-Márquez insistía en la desatención de la crítica hacia un tema transversal de todas sus obras novelísticas hasta ese momento. El otoño del patriarca también habría de desarrollar ese tema. El tema es la soledad. Para García-Márquez, la soledad incluso adquiría la función integradora de toda su obra narrativa.

\footnotetext{
En realidad, uno no escribe sino un libro. Lo difícil es saber cuál es el libro que uno está escribiendo. En mi caso, lo que más se dice es que es el libro de Macondo. Pero si lo piensas con cuidado, verás que el libro que yo estoy escribiendo no es el libro de Macondo, sino el libro de la soledad. (González-Bermejo, 1971, p. 18) ${ }^{1}$
}

Y esto es evidente: la obra de 1967 no lleva por título Cien años de Macondo, sino, de manera contundente, Cien años de soledad. También a González-Bermejo, García-Márquez le asegura que hasta 1970 ningún crítico "ha tocado el punto que a mí me interesaba al escribir el libro, que es la idea de que la soledad es lo contrario de la solidaridad y que yo creo es la esencia del libro" (González-Bermejo, 1971, p. 27). Que Macondo exista en soledad, es decir, en un mundo de individuos -los Buendía y el resto de los habitantes de Macondo- que no logran establecer vínculos solidarios, revela en García-Márquez una denuncia de naturaleza radicalmente política: "la soledad considerada como la negación de la solidaridad es un concepto político. Y es un concepto político importante" (González-Bermejo, 1971, p. 27).

Hasta aquí, García-Márquez es claro: en cuanto anti-valor político -de la polis-, Macondo va en un proceso de aniquilamiento, de desaparición, porque allí no existe un 
tejido societario de reconocimiento por el cual los individuos construyan entre sí un proyecto colectivo más allá de sus propias y de sus aisladas individualidades. Macondo podría ser pensado como la contrapartida de la polis griega: antes que nada, escribe Aristóteles en el

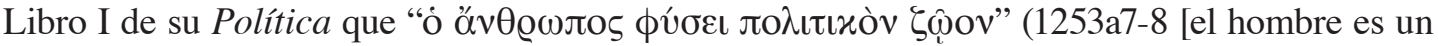

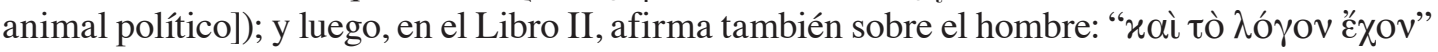
(1334b18-19 [y es poseedor de la palabra]). El hombre es animal de ciudad que usa la palabra. Esto significa, que el hombre es una realidad viviente cuya naturaleza más fundamental construye en diálogo con otras realidades vivientes -con los otros hombres-, en un contexto espacial y temporal compartido y específico: la ciudad (лódıऽ). Los habitantes de Macondo hablan, dialogan, o incluso callan, es decir, tienen la facultad de la palabra, pero no consiguen unirse políticamente. Sin la unión política, societaria, Macondo termina siendo un aglomerado de solitarios. García-Márquez encuentra allí, remarcándolo no una sino cuatro veces, la razón de la comunidad fracasada -que termina no siendo ninguna "comunidad": "La frustración de los Buendía proviene de su soledad, o sea de su falta de solidaridad: la frustración viene de ahí, y la frustración de todo, de todo, de todo, de todo" (González-Bermejo, 1971, p. 27). ${ }^{2}$ Aquí la interpretación de García-Márquez sitúa la noción de soledad menos en un contexto de naturaleza psicológica que en un contexto social. En otras palabras, García-Márquez enfatiza la soledad social, y más radicalmente política, que la soledad vivida en el intimismo de la conciencia individual.

Es por esta razón que lamento no poder seguir a Suzanne Jill Levine en este punto. Sin duda y con buen olfato crítico, la crítica norteamericana, en 1970, ya aseguraba en la introducción a su libro El espejo hablado: Un estudio de Cien años de soledad que, junto con el erotismo y el incesto, la soledad es uno de los "temas básicos del libro" (Levine, 1975, p. 7). Y, al final de ese trabajo crítico, Levine avanza sus tesis de conclusión: "[la soledad] siempre implica un sentimiento subjetivo de abandono y de aislamiento" (Levine, 1975, p. 129). Iré mostrando que lo anterior es cierto, pero lo es únicamente de manera parcial. Cien años de soledad insiste mucho más en la soledad entendida como fracaso - por diversas razones- de proyectos humanos comunes.

\section{Miguel de Unamuno, algo de Umberto Eco, y la voz narrativa de Cien años de soledad}

Para Miguel de Unamuno, en su ensayo “Soledad” de 1905, la soledad muestra un valor positivo de naturaleza paradójica. Situándose en una tradición que muy seguramente viene de los místicos del Siglo de Oro de España, como Santa Teresa de Jesús y como San Juan de la Cruz, la noción de soledad para Unamuno está lejos de ser la práctica propia de un misántropo o un estado psicológico vivido en el más absoluto abandono. "Mi amor a la muchedumbre es lo que me lleva a huir de ella", escribe Unamuno. Y continúa: "Al huirla, la voy buscando. No me llames misántropo. Los misántropos buscan la sociedad y el trato de las gentes; las necesitan para nutrir su odio o su desdén hacia ellas. El amor puede vivir de recuerdos y de esperanzas; el odio necesita realidades presentes" (Unamuno, 1981, p. 31). Unamuno piensa en la soledad como condición necesaria gracias a la cual el individuo consigue romper "la extensa costra del pudor que nos separa a los unos de los otros y de Dios a todos" (Unamuno, 1981, p. 32). Y, asimismo, es en la soledad donde el individuo logra acceder - por fin sin obstáculos- a su yo auténtico. Para resumir groseramente los complejos sentidos de la palabra misticismo, me atrevo a mencionar 
la novela Baudolino (2000), de Umberto Eco. Para Eco, existe, por un lado, el misticismo cósmico que alcanza la conexión perdida con la divinidad -"el Único" y "el Solo"-, y, por otro el misticismo del ermitaño estilita, quien alcanza el vaciamiento total de su interioridad y la pérdida de interés hacia el mundo. El primer misticismo lo encarna el personaje de Hipatia; el segundo, el personaje de Baudolino, al final de la novela del mismo nombre.

En palabras de Hipatia:

\begin{abstract}
Hay que crear una calma absoluta. Entonces nos ponemos en soledad remota ante lo que pensábamos, imaginábamos y sentíamos: se encuentra la paz y la tranquilidad. No experimentaremos ya ni ira ni deseo, ni dolor ni felicidad. Habremos salido de nosotras, extasiadas en absoluta soledad y profunda actitud. (Eco, 2001, p. 438)

Y ahora según Baudolino:

Rezaré, meditaré, me anularé en el silencio. Intentaré alcanzar la soledad remota ante toda opinión e imaginación; intentaré no experimentar ya ni ira ni deseo, y ni siquiera razonamiento y pensamiento; intentaré desvincularme de todo vínculo, volver a lo absolutamente sencillo para no ver ya nada, como no sea la gloria de la oscuridad. Me vaciaré de alma y de intelecto, llegaré más allá del reino de la mente, en la oscuridad llevaré a cabo mi trayecto por vías de fuego. [...] (Eco, 2001, p. 518)
\end{abstract}

Los solitarios místicos de Unamuno están cercanos a la concepción de Hipatia $\mathrm{y}$, asimismo, han de ser considerados héroes, porque son los grandes consoladores de la humanidad (Unamuno, 1981, p. 37). La humanidad les debe a los anacoretas y a los eremitas la formación de la sociedad humana, pues son los solitarios radicales los que, a distancia, en cuanto "pastores de hombres [...] han llevado a los rebaños humanos a la victoria o a la matanza" (Unamuno, 1981, p. 41). Unamuno no contempla la soledad como una deficiencia humana experimentada con insatisfacción. A diferencia de la soledad que presenta GarcíaMárquez en Cien años de soledad, la soledad de Unamuno causa los efectos favorables del autoconocimiento, del conocimiento del prójimo, y del conocimiento de Dios. En Cien años de soledad, el solitario no vive felizmente su condición; esta condición no le hace posible abrirse para el encuentro con los otros; y ni siquiera Dios lo visita en su indeseado refugio de aislamiento. Sería un contrasentido incomprensible que alguno de los personajes de la obra de 1967, sintiera, pensara, o expresara esta exclamación complacida y agradecida de Unamuno: “'Si supieras lo que le debo a mis dulces soledades!” (Unamuno, 1981, p. 34).

Vengo ahora al tema sobre algunas características de la voz narrativa en Cien años de soledad. Esa voz - que es únicamente una sola- toma el protagonismo, y la preminencia sobre el diálogo, porque ese habría sido para García-Márquez el dispositivo verbal más adecuado para contar su historia. En una entrevista que concedió a Gloria Pachón para el periódico colombiano El Tiempo, publicada el 3 de marzo de 1966, García-Márquez teoriza sobre ese dispositivo verbal complejo que estaría usando en la escritura de Cien años de soledad: "[La obra que escribo] es además algo completamente distinto de lo que había hecho hasta ahora. Antes había huido de la retórica y resulta que este libro es pura retórica, ampulosa, con muchas metáforas [. . .], es decir, pura literatura" (García-Márquez, 2001, p. 85). Y, además, según el mismo García-Márquez la voz narrativa de la novela buscaría reproducir, por una parte, el tono de total “willing suspension of disbelief"-para usar las palabras tan justas de Samuel Taylor Coleridge en su Biographia Literaria - con el cual la abuela del escritor contaba cualquier historia -incluso y muy en especial las más inverosímiles-. El 10 de septiembre de 1965, García-Márquez le dará a conocer a Domingo Miliani, crítico y escritor de Venezuela, las características del tono de la voz narrativa que luego dominará los Cien años de soledad. La voz narrativa habría de 
contar los acontecimientos "no como ocurrieron, sino como mi abuela [Tranquilina Iguarán] creyó que ocurrieron" (García-Márquez, 2001, p. 78). Y, por otra parte, la voz narrativa también quiere replicar la cosmovisión de una tía abuela de García-Márquez: Francisca Mejía -o mejor conocida como "La Tía Mama”. Aquí está un recuerdo de García-Márquez sobre La Tía Mama:

\begin{abstract}
La Tía Mama es la protagonista de un historia extraña. [...] Una vez estaba bordando en el corredor cuando llegó una muchacha con un huevo de gallina muy peculiar, un huevo de gallina que tenía una protuberancia. [...] Cada vez que había algo que nadie entendía, iban a la casa y preguntaban y, generalmente, esta señora, esta tía, tenía siempre la respuesta. A mí lo que me encantaba era la naturalidad con que resolvía las cosas. Volviendo a la muchacha del huevo, le dijo: 'Mire usted, ¿por qué este huevo tiene una protuberancia?' Entonces ella la miró y dijo: 'Ah, porque es un huevo de basilisco. Prendan una hoguera ahí en el patio.' Prendieron la hoguera y quemaron el huevo con gran naturalidad. Esa naturalidad creo que me dio a mí la clave de Cien años de soledad, donde se cuentan las cosas más espantosas, las cosas más extraordinarias con la misma cara de palo con que esta tía dijo que quemaran en el patio el huevo de basilisco, que jamás supe lo que era. (García-Márquez, 2001, p. 220)
\end{abstract}

A tal punto la voz narrativa adquiere la preminencia sobre cualquier posibilidad de diálogo, que esa voz vive más bien en la soledad de un monólogo: ni ella tiene conciencia de lectores, ni ella autoriza a sus personajes ningún protagonismo del diálogo dramático. GarcíaMárquez en los Cien años de soledad y el Unamuno escritor que evita el diálogo dramático en sus obras, entran así en contacto. Los unirían razones diferentes, pero en ambos la soledad es una de las razones centrales para que ellos se decidan por una manera específica de escribir.

Sin conciencia de receptor, en Cien años de soledad la voz narrativa estaría enclaustrada en una soledad sin libertad. Esa voz narrativa, tristemente, no podría adherir al sentimiento de libertad en el que consiste la comunicación genuina con el otro. Baudolino justificaba así, desde la experiencia de la libertad, el hecho de contarle su historia a Nicetas Coniates, orador de la corte en Constantinopla: "Sólo cuando he podido contártelo a ti me he sentido libre" (Eco, 2001, p. 41).

Ahora bien, hay quizás un extraño y, sin embargo, probable acuerdo entre Unamuno y el García-Márquez narrador. Cien años de soledad es una novela para la cual la narración se impone, indiscutiblemente, sobre el diálogo dramático. Claro que hay memorables intervenciones citadas o reportadas verbatim de muchos personajes. No obstante, esas intervenciones están aisladas, e igualmente están extraídas irrealmente de cualquier diálogo vivo, posible, actual y efectivo. Unamuno, por su parte, identifica el diálogo -cuya epítome sería el teatro- con la "mentira pura" (Unamuno, 1981, p. 35). Y vuelve Unamuno: "Como no puedo oír la verdad a un hombre cuando habla con otro hombre, ni se la puedo oír cuando me habla, voy a la soledad, me refugio en ella, y allí, a solas, prestando oídos a mi corazón, oigo decir la verdad a todos" (Unamuno, 1981, p. 36). En Cien años de soledad, en contraste, el poco diálogo dramático acaso responda menos a razones de naturaleza antropológica y epistemológica que a razones de naturaleza estética y estilística. El lector de Cien años de soledad puede imaginar sin ninguna dificultad que los personajes de Macondo viven sus vidas según los dramatismos de diálogos construidos con palabras, con insultos, con gritos, con cantos, con carcajadas y aún con silencios: Pilar Ternera sería muy seguramente el personaje más bullicioso de todos; Renata Remedios (Meme), el más silencioso.

La voz narrativa presenta así, por primera vez, a Pilar Ternera:

Por aquel tiempo iba a la casa una mujer alegre, deslenguada, que ayudaba en los oficios domésticos y que sabía leer el porvenir en la baraja. Úrsula le habló de su hijo [José Arcadio]. Pensaba que su desproporción [fálica] era algo tan desnaturalizado como la cola de cerdo del primo. La mujer soltó una risa expansiva que repercutió en la casa como un reguero de vidrio. “Al contrario”, dijo. "Será feliz.” (García-Márquez, 2009, p. 37) 
Ahora bien, incluso sonidos más variopintos y dos bellas hipálages -la cama ardiente, la calle dormida - están ligados a Pilar Ternera. La voz narrativa describe así el camino de José Arcadio hacia el lecho de Pilar Ternera:

\footnotetext{
En la cama ardiente, [José Arcadio] comprendió que tenía que ir a buscarla aunque no fuera capaz. Se vistió a tientas, oyendo en la oscuridad la reposada respiración de su hermano, la tos seca de su padre en el cuarto vecino, el asma de las gallinas en el patio, el zumbido de los mosquitos, el bombo de su corazón y el desmesurado bullicio del mundo que no había advertido hasta entonces, y salió a la calle dormida. (García-Márquez, 2009, pp. 38-39)
}

El silencio largo y final de Meme es más patético y doloroso cuando es leído en contraste con su naturaleza informal, dicharachera, con su clavicordio, con su capacidad para gozar de una compañía multitudinaria y con su amor hacia Mauricio Babilonia -lo confirman fácilmente, por ejemplo, la invitación que extendió a las cuatro monjas y las sesenta y ocho compañeras de su colegio capitalino, así como su genuina capacidad para socializar con los americanos de las plantaciones de banano. A la soledad impuesta de un encarcelamiento religioso, responde como réplica el silencio voluntario de Meme. La voz narrativa registra así el ingreso de Meme al convento donde en el pasado su madre, Fernanda del Carpio, fue educada para ser reina:

\footnotetext{
Todavía [Meme] pensaba en Mauricio Babilonia, en su olor de aceite y su ámbito de mariposas, y seguiría pensando en él todos los días de su vida, hasta la remota madrugada de otoño en que muriera de vejez, con sus nombres cambiados y sin haber dicho nunca una palabra, en un tenebroso hospital de Cracovia. (García-Márquez, 2009, p. 354)
}

Existe una diferencia más entre la soledad en Cien años de soledad y la soledad que Unamuno celebra. Si bien la soledad une transversalmente a todos los personajes de la obra, durante un tiempo de sus vidas o durante toda la vida, la soledad en Cien años de soledad no es la ocasión constante para enfrentar lo que para Unamuno sería "la cuestión humana" (Unamuno, 1981, p. 34). La cuestión humana, es decir, el interrogante más fundamental -y sin respuesta- con el que se enfrentará todo ser humano, tiene un contenido sobrenatural. No está cargada de ningún interrogante sobrenatural la soledad en la novela de García-Márquez. En palabras de Unamuno: "la cuestión humana es la cuestión de saber qué habrá de ser de mi conciencia, de la tuya, de la del otro y de la de todos, después de que cada uno de nosotros se muera" (Unamuno, 1981, p. 34). Muy seguramente "la cuestión humana" de Unamuno, y que se vuelve más apremiante en la soledad de los individuos, no inquieta ni a la voz narrativa, ni a muchos de los personajes de la novela: para ellos la pregunta por la vida después de la vida no es, ya más, una pregunta. Los presagios del Coronel Aureliano Buendía, la visita de los muertos y de La Muerte al mundo de los vivos, la capacidad de los vivos para ver a los muertos y a La Muerte, esos muertos y esa Muerte que circulan en los espacios de los vivos, son una prueba de que en Cien años de soledad ya está respondido el interrogante sobrenatural de Unamuno. Sí hay una vida o existencia después de la muerte, y esa vida -o "pararrealidad" como prefiere llamarla García-Márquez- coexiste y se traslapa con la realidad de quienes todavía no han muerto. Al ser esto así, la soledad en Cien años de soledad no involucra preguntas acuciantes en relación con el binomio mortalidad-inmortalidad. En palabras de García-Márquez a Ernesto González-Bermejo:

Yo he llegado a creer que hay algo que podemos llamar pararrealidad, que no es ni mucho menos metafísica, ni obedece a supersticiones, ni a especulaciones imaginativas, sino que existe como consecuencia de deficiencias o limitaciones de las investigaciones científicas y por eso no podemos llamarla todavía realidad real. (González-Bermejo, 1971, p. 24) 


\section{La soledad para Michel de Montaigne}

Hay un siguiente autor cuyas meditaciones pueden sacar a la luz nuevas características de la soledad en la obra de García-Márquez. En sus Essais, Michel de Montaigne le dedicó al tema de la soledad todo un capítulo: el capítulo XXXVIII del primer volumen de sus Essais. "De la solitude" es un ensayo complejo donde hay un ajuste de cuentas entre lo que para Montaigne serían dos tradiciones clásicas sobre la soledad. Ambas tradiciones son clásicas: por un lado, Plinio el Joven y Cicerón, y en contraste, Séneca y Epicuro. Montaigne estará del lado de Séneca y de Epicuro, y sin descanso elaborará sus argumentos corrosivos en contra de Plinio el Joven y de Cicerón. Antes que nada, Montaigne no se hace ilusiones sobre la bondad intrínseca de la soledad. A pesar de que para él la soledad es un estado deseable, conseguir la soledad no garantiza alcanzar de inmediato sus frutos. En palabras de Montaigne, tomadas de sus Ensayos: "pour nous estre desfaicts de la court et du marché, nous ne sommes pas desfaicts des principaulx torments de notre vie" (Montaigne, 1925, pp. 275-276) [por el hecho mismo de deshacernos de la corte y del mercado, eso no significa que nos hayamos deshecho de los principales tormentos de la vida]. Personajes como Melquíades, como José Arcadio Buendía -el fundador de Macondo- y muy en particular como el Coronel Aureliano Buendía, entienden con Montaigne que soledad significa aislamiento físico del comercio con otras personas. Sin embargo, ese aislamiento físico no conlleva necesariamente la serenidad de espíritu que Montaigne recomienda como objetivo último de la soledad. Además del laboratorio-taller de Melquiades, los más diversos objetos de Macondo parecen envueltos en una atmósfera de aislamiento: hay objetos protagónicos en Cien años de soledad-el daguerrotipo de Remedios, la bella; el talego de lona con los huesos de los padres de Rebeca; los sacos de lona enterrados y llenos de siete mil doscientos catorces doblones dejados al cuidado de Úrsula por un visitante anónimo, por ejemplo- que no únicamente consiguen una autonomía diferenciadora entre cada una de las cosas, que diluye la posesión ontológica hacia cualquier posible dueño, o, en otras palabras en perspectiva gramatical: el genitivo de la preposición de que acompaña al objeto como su complemento de nombre ha sufrido un cortocircuito. Además, la soledad está igualmente instalada en medio de los objetos, impidiéndoles algún tipo de comunicación.

Una ilustración precisa de esos objetos sin humanidad y de esos objetos incomunicados se revela en el galeón español hundido que el patriarca José Arcadio Buendía y sus compañeros expedicionarios encuentran más allá de "la región encantada" (García-Márquez, 2009, p. 21). Así presenta la voz narrativa el galeón español:

Toda la estructura [del galeón] parecía ocupar un ámbito propio, un espacio de soledad y de olvido, vedado a los vicios del tiempo y a las costumbres de los pájaros. En el interior, que los expedicionarios exploraron con un fervor sigiloso, no había nada más que un apretado bosque de flores. (García-Márquez, 2009, p. 22)

La referencia al galeón español no es inútil. Por el contrario, ella merece una consideración especial. Después del título, Levine anota que

La primera mención de la "soledad" en Cien años introduce el concepto de como un síntoma de anacronismo. Durante sus exploraciones del Norte, José Arcadio encuentra las ruinas de un viejo galeón español que está descrito como "un espacio de soledad y de olvido". (Levine, 1975, p. 129)

Ahora bien: a diferencia de Levine, yo me atrevo a lanzar una conjetura diferente, sin apostar por una afirmación definitiva: El hecho de que los restos en ruinas del galeón sean españoles apuntaría al vínculo ya inexistente entre el mundo de los Buendía y España. El galeón es un medio de transporte inútil ahora, esto es, un rezago del pasado cuando al menos 
la comunicación con otras tierras era posible. Habría habido anacronismo si el galeón hubiera aparecido en perfecto estado y todavía navegando. El mundo de los Buendía está frecuentado aún por otro modo de la soledad y por otra forma del olvido: soledad, porque España es un asunto del pasado; olvido, porque España en el mundo de los Buendía es ruina enterrada, inmóvil e inútil, y porque esa misma España no piensa más en galeones -desperdicios de un imperio que ya no es más y a los que ni la memoria de España tendría la tendencia a visitar-.

Con todo, los solitarios en los Cien años de soledad no viven serena y alegremente su soledad. ¿Por qué el laboratorio-taller de Melquíades no asegura una soledad tranquila? Montaigne respondería: porque esos solitarios llevan consigo, a sus respectivas soledades, insatisfacciones que aún no los abandonan. Escribe Montaigne:

\footnotetext{
l'ambition, l'avarice, l'irresolution, la peur et les concupiscences ne nous abandonnent point, pour changer de contree [...] elles nous suyvent souvent jusques dans les cloistres et dans les escholes de philosophie: ny les deserts, ny les rochiers creusez, ni la haire, ny les jeusnes, ne nous en desmeslent (Montaigne, 1925, p. 276)

[la ambición, la avaricia, la irresolución, el temor y las concupiscencias en lo absoluto nos abandonan simplemente por cambiar de lugar [...] ellos a menudo nos siguen hasta en los claustros y hasta en las escuelas de filosofía: y tampoco nos liberamos de ellos ni en desiertos, ni en rocas con cavernas, ni con vestimentas hechas con el pelaje de animales, ni con ayunos]
}

¿Cuál sería entonces la solución? Montaigne responde con estas palabras del poeta latino Horacio, tomadas de la primera de sus Epistulae: "Ratio et prudentia curas, non locus effusi late maris arbiter, aufert" (Liber Primus I, Epistula xviii, Lineae 25-26) [Estar en un lugar desolado desde donde sea posible ver el amplio espacio abierto del mar no permite alejarse de la preocupación. Esto lo consiguen la razón y la prudencia]. La soledad feliz es para Montaigne un retiro menos físico que psicológico, un retiro gozoso hacia sí mismo. Y allí -no un lugar físico, sino más bien un modo de existir-, ese retiro interior libre de toda dependencia ajena lleva por nombre "la vraye solitude" (Montaigne, 1925, p. 277).

Sería posible para Montaigne pensar que el frenético activismo de Úrsula Iguarán no necesariamente tiene que obstaculizar la "verdadera soledad". El quietismo mudo en el que cae Meme, y su aislamiento en un convento de la ciudad lejana e innombrada -sin duda Bogotá-, son una falsa soledad. Tampoco, en términos de Montaigne, es existencialmente verdadera la soledad que de manera trágica, cómica y paródica traza un círculo de tiza: si bien aislado de todos cuando él está en la cima de su poder político y militar, el Coronel Aureliano Buendía sigue atrapado en las redes de la gloria -o de la fama-. Las palabras de Montaigne polemizan directamente contra Cicerón, para quien la soledad de todo retiro de la vida pública sería un simple medio. Según Montaigne, Cicerón se limitó a instrumentalizar la soledad, porque él "dict vouloir employer sa solitude et sejour des affaires publicques à s'en acquerir par ses escripts une vie immortelle" (Montaigne, 1925, p. 283) [dijo querer emplear su soledad y su separación de los asuntos públicos con el fin de conseguir una vida inmortal por medio de sus escritos]. La posición de Montaigne no podría ser más opuesta. Con una imagen etológica, el principio práctico de Montaigne quiere ser contundente: "il faut faire comme les animaux qui effacent la trace à la porte de leur taniere" (Montaigne, 1925, p. 287) [hay que hacer como los animales que borran las propias huellas a la entrada de sus madrigueras].

El Coronel Aureliano Buendía puede haberla buscado, o no. En todo caso, fue en gran parte gloria eso que resultó de sus actos. Hay dos tipos de soledad que agobian al Coronel Aureliano Buendía. En primer lugar, vuelve al recuerdo la imagen del coronel que camina, pero sin tocar o abrazar a alguien, mientras cerca de sus pies un subalterno siempre traza un círculo 
de tiza de seis metros de diámetro. El personaje de Nicetas Coniates conjetura, al dialogar con Baudolino: "Y quizás es pasión más arrolladora mandar que hacer el amor" (Eco, 2001, p. 387). El Coronel Aureliano Buendía habría sido el títere de esa pasión, la cual no revela al otro en su individualidad irreductible, sino que aislaría a quien manda y a quien obedece, porque el que obedece queda convertido en un simple instrumento de los deseos de quien manda. Otra, muy distinta, sería la revelación del otro cuando la relación entre individuos es establecida desde el amor. Por haber vivido desde la soberbia la pasión de mandar, la voz narrativa comunica la conclusión a la que llega Úrsula madre sobre su hijo el Coronel Aureliano Buendía: "[Úrsula] llegó a la conclusión de que aquel hijo por quien ella habría dado la vida era simplemente un hombre incapacitado para el amor" (García-Márquez, 2009, p. 299). ${ }^{3}$

En segundo lugar, estaría la soledad del retiro doméstico. El laboratorio-taller de Melquíades adquiere en la casa de los Buendía la función de madriguera para el Coronel Aureliano Buendía y para algunos personajes más -todos personajes masculinos: ¿por qué será esto? Aun cuando en el laboratorio-taller de Melquíades la velocidad ruidosa de la casa no logra ingresar, el mágico y enigmático y ciertos momentos desatendido resguardo no trae la serenidad de la madriguera según la imagen de Montaigne-. Montaigne también volverá al mundo de la arquitectura humana al hablar de "boutique" o trastienda, a modo de espacio físico necesario para el retiro dentro del propio espacio doméstico. Tiempo después de su existencia bélica, la voz narrativa de los Cien años de soledad informa sobre el Coronel Aureliano Buendía:

\footnotetext{
Taciturno, silencioso, insensible al nuevo soplo de vitalidad que estremecía la casa, el coronel Aureliano Buendía apenas si comprendió que el secreto de una buena vejez no es otra cosa que un pacto honrado con la soledad. Se levantaba a las cinco después de un sueño superficial, tomaba en la cocina su eterno tazón de café amargo, se encerraba todo el día en el taller, y a las cuatro de la tarde pasaba por el corredor arrastrando un taburete, sin fijarse siquiera en el incendio de los rosales, ni en el brillo de la hora, ni en la impavidez de Amaranta, cuya melancolía hacía un ruido de marmita perfectamente perceptible al atardecer, y se sentaba al atardecer en la puerta de la calle hasta que se lo permitían los mosquitos. Alguien se atrevió alguna vez a perturbar su soledad.

- ¿Cómo está, coronel? -le dijo al pasar.

-Aquí -contestó él-. Esperando que pase mi entierro. (García-Márquez, 2009, pp. 242-243) ${ }^{4}$
}

Y mucho menos, para Montaigne la soledad verdadera consiste en entregarse al estudio: ¿Cuántos de los Buendía creyeron, muy seguramente junto con Melquíades y con el patriarca José Arcadio Buendía, que estudiar para primero descifrar los manuscritos del gitano, y luego, para por fin saber, tendría como efecto la soledad serena, satisfecha, esa del solitario feliz y agradecido? Montaigne escribió: "Puisque nous entreprenons de vivre seuls, et de nous passer de compaignie, faisons que nostre contentement despende de nous; desprenons nous de toutes les liaisons qui nous attachent à aultruy; gaignons sur nous de pouvoir à bon escient vivre seuls, et y vivre à nostre ayse" (Montaigne, 1925, p. 277) [Puesto que emprendemos la tarea de vivir solos, y de desentendernos de compañía, ¡hagamos que nuestro regocijo dependa de nosotros! ¡Desprendámonos de todos los lazos que nos unen al prójimo! ¡Ganemos sobre nosotros el poder vivir solos con conocimiento de causa, y allí vivir tranquilamente!]. Montaigne identificará las cosas que pueden convertirse en obstáculos para la soledad. Ellas están nítidamente ilustradas por José Arcadio Buendía, el hijo del primer Buendía, en su relación con las mujeres; por Úrsula en relación con su familia biológica; por el patriarca José Arcadio Buendía en su ansia de riquezas y de aventuras; y por Fernanda del Carpio en su hipocondría insigne. Montaigne es contundente: "Il fault avoir femmes, enfants, biens, et sur tout de la santé, qui peult; mais non pas s'y attacher en maniere que nostre heur en despende: il se fault reserver une arriere boutique, toute nostre, toute franche, en laquelle nous 
establissions nostre vraye liberté et principale retraicte et solitude" (Montaigne, 1925, p. 278) [Hay que tener mujeres, hijos, bienes, y sobre todo salud, quien pueda tenerla; pero no hay que apegarse de tal manera a eso que de ello dependa nuestra felicidad: hay que reservarse para sí una pequeña trastienda, del todo nuestra, del todo fiel, donde establezcamos nuestra verdadera libertad, nuestro lugar principal de retiro y nuestra soledad].

\section{5. ¿Soledad como talante de una época? Zubiri y García-Márquez}

Cierro mis argumentos lanzando una conjetura y luego una sugerencia. La conjetura permitiría leer la novela de García-Márquez como expresión patente de una de las evidencias espirituales de una época de la cultura de Occidente. Esa novela armonizaría con lo que vio con lucidez filosófica el filósofo español Xavier Zubiri. Una analogía muy rústica del espiritismo, y otra más de la meteorología, justificarían probablemente el contacto de estos dos autores. Vayan las dos analogías: grandes escritores y grandes pensadores dispondrían de la facultad para ser media o termómetros por los cuales es comunicada una época o los sentimientos colectivos de expansión amplia. O también: esos escritores y esos pensadores expresan en sus obras la temperatura en el talante específico de una época.

Hace exactamente setenta años, Zubiri componía el diagnóstico de las circunstancias espirituales de Europa occidental, en su tradición greco-cristiana. La expresión usada por Zubiri para concluir con su diagnóstico no podría estar más en consonancia con el espíritu de la novela que García-Márquez escribiría en 1967, en ciudad de México. Desde Barcelona, en 1942, en su ensayo titulado "Nuestra situación intelectual", Zubiri certificaba el triunfo de lo que para él eran las tres desviaciones contemporáneas en la comprensión de la verdad, a saber: el positivismo, el pragmatismo y el historicismo. Para el primero, la realidad se agota en simples datos empíricos; para el segundo, la realidad necesita ser manipulada técnicamente en función de un éxito urgente; para el tercero, "la verdad no existe sino desde una situación [de realidad] determinada [cronológica y geográficamente]" (Zubiri, 1981, p. 19). A su manera, García-Márquez también habría tratado de luchar contra esas desviaciones contemporáneas de la verdad: Con la presencia ubicua y cierta de la pararrealidad, García-Márquez evitaría caer en la aridez del positivismo; mostrando las nefastas consecuencias de los animalitos de dulce de Úrsula -entre otras más aventuras económicas emprendidas y sufridas en Macondo-, García-Márquez criticaría el pragmatismo desalmado; y con la insistencia, a través de varias generaciones, en la veracidad del reporte ex visu y ex auditu de la masacre de las bananeras, García-Márquez apostaría por una verdad ni diluida ni dependiente de circunstancias históricopolíticas y geográficas.

Frente al mundo avasallado por el historicismo, por el pragmatismo y por el positivismo, Zubirí recurrió a estas expresiones - por cierto nada optimistas- para describir las consecuencias antropológicas de esos tres "ismos": "Intelectualmente", apunta Zubiri, "no le queda al hombre de hoy más que el lugar ontológico donde pudo inscribirse la realidad del mundo, de Dios y de su propia existencia. Es la soledad absoluta" (Zubiri, 1981, p. 31). En Cien años de soledad, la humanidad de Macondo también vive su soledad de varias maneras. Ellas hacen pensar en las palabras de Zubiri: porque la soledad de Macondo es vivida como desconexión metafísica con las cosas del mundo, como proyectos frustrados de la esperanza, como incapacidad inevitable para amar, como ausencia de solidaridad comunitaria, como aniquilamiento bélico entre individuos y Estado, como abandono de los gobiernos centrales, como violencia de sangre y de leyes arbitrarias, como geografía usualmente indómita, como azotes de un clima empecinado en 
la crueldad, como el antes y el después del ejercicio ilimitado del poder -del Coronel Aureliano Buendía, García-Márquez dirá: “ese orfebre solitario, Aureliano Buendía, que resultó ser el coronel" (González-Bermejo, 1971, p. 29)- y, en fin, como ausencia silenciosa de Dios.

En sus dos documentos, García-Márquez y Zubiri -el primero, según las intuiciones de la palabra poética; el segundo, según las abstracciones del concepto filosófico- estarían tal vez traduciendo verbalmente el sentir espiritual hacia mitad del siglo XX occidental. No obstante, hay claras marcas lingüísticas de que ambos autores no concuerdan completamente: por una parte, en las líneas finales de Cien años de soledad están el adverbio siempre repetido dos veces, y la seguridad asertiva del adverbio no; por otra, en "Nuestra situación espiritual" la expresión compleja de dos conjunciones - una adversativa, pero, y otra condicional, si- y el optimismo de las figuras literarias -una sinestesia: umbrae silentes; un oxímoron: soledad sonora- cierran esperanzadoramente el ensayo de Zubiri. Así, frente al apocalipsis fatal de García-Márquez, Zubiri opone aún la certidumbre de algunas reservas de confianza moderada.

Es indispensable contrastar las líneas finales de ambos documentos. Aquí está, entonces, el tan conocido final de la novela: "que todo lo escrito en [los pergaminos] era irrepetible desde siempre y para siempre, porque las estirpes condenadas a cien años de soledad no tenían una segunda oportunidad sobre la tierra" (García-Márquez, 2009, p. 495). ${ }^{5}$ En contraste, Zubiri no habla de algo ya escrito, sino más bien de un problema situacional de época: se trata menos de la necesidad presente originada en un pasado siempre inmodificable, que de un futuro humano difícil -surgido por cierto de antecedentes históricos, pero que todavía no ha sido jugado del todo. "Pero si, por un esfuerzo supremo [anhela esperanzadamente Zubiri] logra el hombre replegarse sobre sí mismo, siente pasar por su abismático fondo, como umbrae silentes, las interrogantes últimas de la existencia. Resuenan en la oquedad de su persona las cuestiones acerca del ser, del mundo y de la verdad" (Zubiri, 1981, p. 31).

Esto llevaría a pensar que mientras para Zubiri la soledad humana asume la forma posible de un final abierto hacia otro comienzo probable y problemático, la soledad en los Cien años de soledad sería un cierre absoluto, de punto final. Antes de que apareciera Cien años de soledad, en 1963 y de nuevo para Eco -número 40- Volkening redactó un penetrante ensayo: "García Márquez y el trópico desembrujado". En esas páginas, Volkening descubría el meollo filosófico de la soledad en García-Márquez: antes que nada, ella es consecuencia de uno de los más radicales principios ontológicos, esto es, el principium individuationis. Volkening afirma:

\footnotetext{
Para García Márquez, la individualidad es lo que por ella se entiende, partiendo de la acepción literal del término: el hombre tal cual, algo indiviso e irreductible, una totalidad, quizá modesta, pero no por eso menos invulnerable, y el hombre en medio del ajetreo de la vida cotidiana, de las multitudes aglomeradas en la plaza de mercado, de la familia e insípida palabrería de comadres y compadres de golpe descubre que está solo, solo con su destino, su enfermedad, su infortunio y su muerte. (Volkening, 1976b, p. 103)
}

No estoy de acuerdo con Volkening en su aseveración de que haya una revelación súbita de la soledad en Cien años de soledad. Por el contrario, apruebo extender su comprensión de ella para la novela que será publicada cuatro años después. Allí, la soledad es comprendida, primero, como una consecuencia del carácter indefectiblemente singular de los seres humanos $\mathrm{y}$, segundo, con la vivencia consciente de los fracasos causados por la individuación: Es inútil que los humanos de Macondo constantemente intenten crear puentes más o menos sólidos entre su singularidad monádica - ¿un pleonasmo?-.

Con todo, el final de Cien años de soledad conduce a la desaparición de la soledad por medio de una solución terrible: sin hombres, no puede haber solitarios. El último hombre 
solitario de Macondo ni siquiera existe más en soledad: porque ya no habría más hombres -y por esto, ninguna posibilidad para la humanidad-. O, quizás, es necesario que la humanidad evite repetir los senderos humanos de Macondo. "Pues estaba previsto que la ciudad de los espejos (o de los espejismos) sería arrasada por el viento y desterrada de la memoria de los hombres" (García-Márquez, 2009, p. 495). Sí: Cien años de soledad es un libro triste. Una humanidad que busque construir otros espacios de vida tendría que hacerlo fuera y lejos de Macondo, aprendiendo de él, libre de la soledad que aniquiló ese experimento de la imaginación humana. Desde un punto de vista biográfico, y también acaso por razones de naturaleza geográfica -el Caribe- y de naturaleza psicológica -una familia numerosa, la profesión del periodismo, la práctica de la amistad-, la soledad en Cien años de soledad podría ser pensada como la radiografía invertida del mundo que, visceralmente, García-Márquez teme y no desea. ${ }^{6}$ El mundo propio de García-Márquez parece haber sido siempre un mundo generoso en lazos societarios, abigarrado de personas, hiperbólico en las experiencias de compañías humanas. La vida del autor de Cien años de soledad podría ser vista como un ejercicio de lucha, desesperado y constante, por conjurar la soledad de Macondo -entendida esta soledad como falta de lazos solidarios en medio de las más diversas formas de la falsa "compañía" humana-.7

Y llego por fin a una sugerencia, para seguir pensando: creo que sí habría un tipo de soledad positiva, valiosa, incluso alegre y juguetona, en Cien años de soledad. Esa soledad con valor tendría que ver con la serenidad de los muertos en su propia muerte -salvo en el caso de Melquíades, que volvió a Macondo después de morir, "porque no pudo soportar la soledad" (García-Márquez, 2009, p. 66)-, y con la manera como, desde la muerte, los muertos brindan una cercanía estrecha y solidaria a quienes todavía viven. Este será, quizás y sin embargo, un tema para un futuro documento crítico.

\section{Notas}

1. En Modernism: The Lure of Heresy, Peter Gay caracteriza la soledad en el libro de 1967 primero como un "subtexto," como un "pathos," como "un lado melancólico," y que a la vez que "merece más atención de la que ha recibido," es un "aspecto mucho más fácil de identificar que de comprender" (2008, pp. 470-471).

2. Acaso sirva entender a Macondo retomando uno de los oxímorones usados por el personaje de Hipatia en Baudolino, de Umberto Eco, cuando ella procede a caracterizar negativamente a Dios: Al igual que Dios, Macondo sería una "multiplicidad solitaria” (Eco, 2001, p. 431).

3. Es muy significativo que, en su intento de comprender el sentido de la soledad en la obra de GarcíaMárquez deslice sutilmente sus reflexiones al binomio amor/sexo. Esto lo lleva a cabo sin transiciones argumentativas. Con Gay sería posible asegurar que para García-Márquez sus personajes persisten en una soledad insatisfactoria porque en sus vidas hay simplemente sexo, y no alcanzan a vivir en amor. En palabras de Gay: "A falta de amor, es la soledad la oscura compañera" (2008, p. 472). Yo diría: limitados únicamente al sexo, la soledad nombraría un estado de vida donde es imposible el acceso efectivo y profundo y constante al otro, más allá de las fronteras melancólicas de la individualidad. Sin el amor que sería la condición para ese acceso, no habría encuentro verdadero con otros hombres y con otras mujeres. Gay concluye: "El amor no lo puede todo [en la obra de García Márquez], pero sin él no hay conquista alguna que valga la pena" (2008, p. 472).

4. $\quad$ En El laberinto de la soledad (1950), de Octavio Paz, está escrito: "La madurez no es etapa de soledad. El hombre, en lucha con los hombres o con las cosas, se olvida de sí en el trabajo, en la creación o en la construcción de objetos, ideas e instituciones" (Paz, 1950, p. 182). Levine descubre que en "Cien años, la palabra 'soledad' aparece más veces en referencia al coronel Aureliano Buendía que con respecto a cualquier otro personaje" (Levine, 1975, p. 140). Con buen tino, las proposiciones criticables - pero 
contundentes de Paz- le permiten a Levine asegurar que Úrsula es el personaje menos solitario de la novela; el coronel Aurelio Buendía, el más solitario. El activismo de compromiso familiar de Úrsula le garantizaría el olvido de su propia soledad -según Paz-, mientras que el casi quietismo del coronel, su hijo, en razón de las guerras fracasadas, lo mantiene en hiper-conciencia de sí. Esta hiper-conciencia de sí lo lleva a la lucidez de su ineludible abandono existencial. Ahora bien: ¿García-Márquez leyó el importantísimo ensayo de Paz de 1950? A este respecto, responde Conrado Zuluaga: "No veo posible 'estar seguros' de la posibilidad de que García Márquez haya leído El laberinto de soledad, pero sí me parece una hipótesis factible. Y esto si tenemos en cuenta: 1. Su 'tutor' en México es Álvaro Mutis; 2. García Márquez es curioso e inquieto; 3 . Sus compañeros de trabajo y demás, son Carlos Fuentes, Juan Rulfo, Luis Alcoriza y otros más; y 4. No creo que alguien con una carrera como escritor al llegar a ese país, le pase desapercibido e ignorado un documento de esa magnitud y trascendencia, no solo para los mexicanos, sino asimismo para todos los latinoamericanas" (Zuluaga, comunicación personal, 21 de marzo de 2013).

5. Quizás sea posible suavizar la fatalidad de estas líneas finales: ¿Habría otras estirpes libres de esa condena? Si lo escrito en los pergaminos de Melquíades es irrepetible, es decir, ya no volverá a ocurrir más, ¿la humanidad puede ser optimista y suponer como sobrepasado, por fin, el destino de Macondo?

6. A pesar de mi desconocimiento supino de la psicología, acuño ahora la expresión fobia a la soledad. En su cuento de "La siesta del martes" (1962), recuerdo estas palabras que usa la voz narrativa, mientras reconstruye en un flash-back el ingreso furtivo de Carlos Centeno en la residencia de la señora Rebeca: "Orientándose no tanto por el ruido de la cerradura como por un terror desarrollado en ella por 28 años de soledad, [la viuda solitaria] localizó en la imaginación no sólo el sitio donde estaba la puerta sino la altura exacta de la cerradura [que Centeno trataba de violentar]." (García-Márquez, 1983, p. 125). De manera intensa e incontrolable, esa fobia o terror a la soledad bien podría revelarse en una de las soledades humanas más definitivas: la del cuerpo humano muerto. En Gabriel García Márquez: Una vida, Gerald Martin escribió: "García Márquez ha vivido con tres terrores primordiales, conectados entre sí, a la par que increíblemente contradictorios: el temor a la muerte y a ser enterrado (o, peor, a ser enterrado vivo); el terror a tener que enterrar a otros, y el terror a que alguien, cualquiera, no reciba sepultura" (Martin, 2009, p. 132).

7. La soledad como tonalidad afectiva, siempre acechante e indeseada, y de la que conviene huir, está ejemplificada de manera angustiosa durante los domingos que García-Márquez vivió en Bogotá, entre 1947 y 1948. Martin escribirá sobre ese período: "A fin de escapar a la soledad de los domingos, [García Márquez] hacía interminables viajes en tranvía por la ciudad, monótona, leyendo y reflexionando" (Martin, 2009, p. 128).

\section{Bibliografía}

Aristóteles. (s.f.). Política. API $\Sigma$ TOTH $\Lambda$ OY $\Sigma$ T $\Omega$ N $\Pi O \Lambda I T I K \Omega N$. [Versión digital]. http:// www.perseus.tufts.edu/ [Consulta 4 de abril de 2012].

Coleridge, S.T. (2004). Biographia Literaria. [Versión digital]. http://www.gutenberg.org [Consulta 3 de marzo de 2012].

Eco, U. (2001). Baudolino. (H. Lozano-Miralles, tr.). Barcelona: Lumen.

Faulkner, W. (1942). The Bear. Go Down, Moses. (189-331). New York: Random House.

García-Márquez, G. (1983). La siesta del martes. Todos los cuentos. (121-127). Bogotá: Oveja Negra; Seix Barral.

García-Márquez, E. (2001). Tras las claves de Melquíades: Historia de Cien años de soledad. Bogotá: Norma.

García-Márquez, G. (2009). Cien años de soledad. Buenos Aires: Sudamericana. 
Gay, P. (2008). Modernism: The Lure of Heresy from Baudelaire to Becket and Beyond. New York: W. W. Norton.

González-Bermejo, E. (1971). Con Gabriel García Márquez: Ahora doscientos años de soledad. Cosas de escritores: Gabriel García Márquez, Mario Vargas Llosa, Julio Cortázar. (11-51). Montevideo: Biblioteca de Marcha.

Gutiérrez-Girardot, R. (2011). La imagen de Colombia en Cien años de soledad de Gabriel García Márquez. (J.G. Gómez-Giraldo, tr.). (Vol. 1, 225-245). Medellín: UNAULA.

Horatius Flaccus, Q. (s.f.) Epistulae. [Versión digital]. http://www.thelatinlibrary.com/hor.html/ [Consulta 7 de abril 2012].

Levine, S.J. (1975). El espejo hablado: Un estudio de Cien años de soledad. Caracas: Monte Ávila.

Martin, G. (2009). Gabriel García Márquez: Una vida. (E. Vázquez-Nacarino, tr.). Bogotá: Random House Mondadori.

Montaigne, M. de. (1925). Essais de Montaigne $\overline{\overline{\overline{2}}}$. Leclerc (Ed.)]. Frères.

Paz, O. (1950). El laberinto de la soledad. México: Cuadernos Americanos.

इ Comedy. (1958). Life Magazine. 44 (5), 8-9.

Unamuno, M. de. (1981). Soledad. Madrid: Espasa-Calpe.

Volkening, E. (1976a). Anotado al margen de Cien años de soledad. Ensayos I: Destellos criollos. (119-156). Bogotá: Instituto Colombiano de Cultura.

Volkening, E. (1976b). García Márquez y el trópico desembrujado. Ensayos I: Destellos criollos. (93-107). Bogotá: Instituto Colombiano de Cultura.

Zubiri, X. (1981). Nuestra situación intelectual. Naturaleza, Historia, Dios. (3-31). Madrid: Editora Nacional.

Zuluaga, C. (21 de marzo de 2013). Comunicación personal. [Correo electrónico]. 
